\title{
Civil courts coping with Covid-19, de Bart Krans y Anna Nylund (Coords.), Eleven International Publishing, The Hague, $2021^{1}$
}

\section{Santiago PEREIRA CAMPOS 2}

La editorial Eleven International Publishing acaba de publicar en La Haya, Países Bajos, el libro "Civil Courts coping with Covid-19", obra colectiva en la que tuve el honor de participar.

Los editores de la obra son Bart Krans (Profesor Titular en la Universidad de Leiden, Holanda, donde ocupa la cátedra de Derecho Privado y Derecho Procesal Civil) y Anna Nylund (Profesora Titular de Derecho en la Universidad de Tromsø).

La imprevista pandemia de Covid-19 tuvo impactos de gran relevancia en los sistemas de justicia de todos los países, que demostraron no estar preparados para el inmenso desafío de garantizar el acceso a justicia y cumplir con las medidas sanitarias. Ello determinó que la prestación del servicio de justicia se viera gravemente

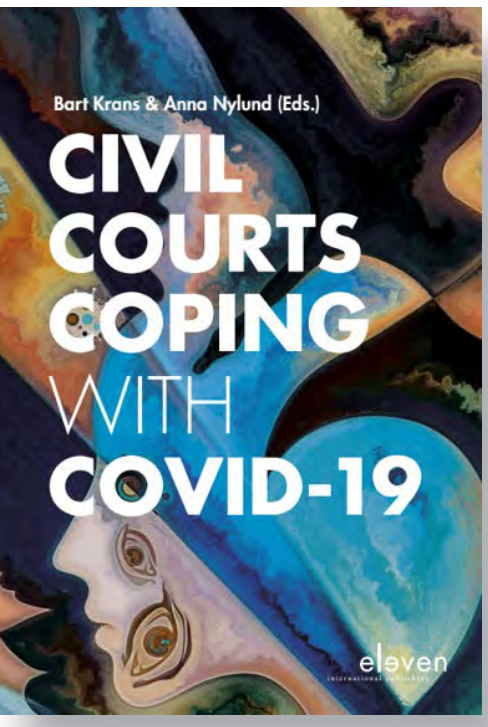
afectado en casi todos los Estados.

Frente a ello, la doctrina, la judicatura, la abogacía y la sociedad toda, debieron buscar rápidamente soluciones que permitieran restaurar el servicio, mediante transformaciones sin precedentes en los procesos judiciales. Los tribunales han demostrado ser creativos e innovadores en sus respuestas a la pandemia, y en su capacidad para implementar digitalización de trámites y audiencias remotas.

El libro contiene un estudio comparativo de cómo los tribunales en 23 países han hecho frente a la pandemia, abordando innovaciones y adaptaciones a los procesos judiciales, que facilitan el salto digital y, a su vez, generan nuevas preocupaciones. Incluye informes de Australia, Belgica, Brasil, Canadá, China, Croacia, Dinamarca, Reino Unido, Finlandia, Francia, Alemania, Italia, Japón, Lituania, Países Bajos, Noruega, Perú, Polonia, Singapur, Slovenia, Taiwan, Uruguay y Estados Unidos y un excelente análisis comparativo de los editores.

En la obra, los autores discutimos las implicaciones de la digitalización, cómo garantizar la igualdad de acceso a los tribunales, cuestiones novedosas relativas al derecho a un juicio justo en procesos telemáticos, el papel de la resolución de disputas durante la pandemia por vías diferentes al proceso judicial, y las raíces de la resistencia a la digitalización. Varias contribuciones también abordan cómo las innovaciones durante la pandemia pueden transformar el litigio civil en el futuro.

1 La obra es de open access a través del siguientelink: https://boeken.rechtsgebieden.boomportaal.nl/publicaties/9789462362048\#2 2 Director de la Maestría en Derecho Procesal y Litigación, Director del Postgrado en Derecho Procesal Aplicado y Profesor Titular de Derecho Procesal en la Universidad de Montevideo. 
En situaciones de especial dificultad, las instituciones y sus personas se dan por vencidas o sacan lo mejor de sí para salir adelante. Es probable que en un contexto de normalidad habría llevado décadas construir la infraestructura, implementar los nuevos procesos de trabajo y completar los otros numerosos desarrollos necesarios para dar el salto necesario e inevitable hacia la digitalización. Como señalan los editores, la pandemia ha desatado un flujo de creatividad e innovación sin precedentes entre los tribunales, la judicatura y la abogacía. Simultáneamente, la pandemia ha puesto de manifiesto en muchos casos la lentitud de los tribunales para digitalizar, así como algunas de las razones subyacentes para resistir a las audiencias remotas y la resolución de disputas en línea (ODR). Mientras que algunas de las razones de esta resistencia están bien justificadas y son oportunas, algunas otras parecen originarse de la fricción que inevitablemente conlleva un cambio culturar.

Sin duda que el salto tecnológico y otros avances han abierto nuevos horizontes en el futuro de la justicia civil. De ello también trata este libro. 